\title{
Fredholm's third theorem for second-order singular Dirichlet problem
}

\section{Alexander Lomtatidze ${ }^{1,2}$ and Zdeněk Oplušti $2^{2^{*}}$}

"Correspondence:
oplustil@fme.vutbr.cz
2Institute of Mathematics, Faculty of
Mechanical Engineering, Brno
University of Technology,
Technická 2, Brno, 61669, Czech
Republic
Full list of author information is
available at the end of the article

${ }^{*}$ Correspondence:

oplustil@fme.vutbr.cz

Technická 2, Brno, 616 69, Czech

Full list of author information is

available at the end of the article

\section{Abstract}

Consider the singular Dirichlet problem

$$
\begin{aligned}
& u^{\prime \prime}=p(t) u+q(t) \\
& u(a)=0, \quad u(b)=0
\end{aligned}
$$

where $p, q:] a, b[\rightarrow \mathbb{R}$ are locally Lebesgue integrable functions. It is proved that if

$$
\int_{a}^{b}(s-a)(b-s)[p(s)]_{-} d s<+\infty \text { and } \int_{a}^{b}(s-a)(b-s)|q(s)| d s<+\infty
$$

then Fredholm's third theorem remains true.

MSC: 34B05

Keywords: singular Dirichlet problem; Fredholm's third theorem

\section{Introduction}

Consider the boundary value problem

$$
\begin{aligned}
& u^{\prime \prime}=p(t) u+q(t), \\
& u(a)=0, \quad u(b)=0,
\end{aligned}
$$

where $p, q \in L_{\mathrm{loc}}(] a, b[)$. We are mainly interested in the case, when the functions $p$ and $q$ are not integrable on $[a, b]$. In this case, the problem (1), (2) is said to be singular. It is proved in [1] that if

$$
\int_{a}^{b}(s-a)(b-s)[p(s)]_{-} d s<+\infty
$$

and

$$
\int_{a}^{b}(s-a)(b-s)|q(s)| d s<+\infty
$$

then, for the singular problem (1), (2), the Fredholm alternative holds. More precisely, the following theorem is true.

\section{Springer}

O2014 Lomtatidze and Opluštil; licensee Springer. This is an Open Access article distributed under the terms of the Creative Commons Attribution License (http://creativecommons.org/licenses/by/2.0), which permits unrestricted use, distribution, and reproduction in any medium, provided the original work is properly cited. 
Theorem 1.1 ([1, Theorem 0.1]) Let (3) hold. Then the problem (1), (2) is uniquely solvable for any $q$ satisfying (4) iff the corresponding homogeneous equation

$$
u^{\prime \prime}=p(t) u
$$

has no nontrivial solution satisfying (2).

The aim of this paper is to show that, under the assumption (3), the Fredholm's third theorem remains true. Before formulation of the main results, we introduce the following notation.

$\mathbb{R}$ is the set of real numbers.

For $x \in \mathbb{R}$, we put $[x]_{-}=\frac{1}{2}(|x|-x)$.

$C(I)$, where $I \subset \mathbb{R}$, is a set of continuous functions $u: I \rightarrow \mathbb{R}$.

For $u \in C([\alpha, \beta])$, we put $\|u\|_{[\alpha, \beta]}=\max \{|u(t)|: t \in[\alpha, \beta]\}$.

$A C_{\text {loc }}^{\prime}(] \alpha, \beta[)$ is the set of functions $\left.u:\right] \alpha, \beta[\rightarrow \mathbb{R}$, which are absolutely continuous together with their first derivative on every closed subinterval of $] \alpha, \beta[$.

$L_{\mathrm{loc}}(] \alpha, \beta[)$ is the set of functions $\left.p:\right] \alpha, \beta[\rightarrow \mathbb{R}$, which are Lebesgue integrable on every closed subinterval of $] \alpha, \beta[$.

By $f(a)$ (resp., $f(b))$ we denote the right (resp., left) limit of the function $f:] a, b[\rightarrow \mathbb{R}$ at the point $a$ (resp., $b$ ).

By a solution of equation (1) we understand a function $u \in A C_{\mathrm{loc}}^{\prime}(] a, b[)$, which satisfies it almost everywhere in $] a, b$ [. A solution of equation (1) satisfying (2) is said to be a solution of the problem (1), (2).

We will say that a certain property holds in $] \alpha, \beta[$ if it takes place on every closed subinterval of $] \alpha, \beta[$.

Recall that we consider the problem (1), (2), where $p, q \in L_{\mathrm{loc}}(] a, b[)$.

Theorem 1.2 Let (3) hold. Then the homogeneous problem (1a), (2) has no more than one, up to a constant multiple, nontrivial solution.

Remark 1.1 Below we will show (see Proposition 2.1) that if (3) holds and $u_{0}$ is a nontrivial solution of (1a), (2), then there exists $r_{0}>0$ such that

$$
\left|u_{0}(t)\right| \leq r_{0}(t-a)(b-t) \quad \text { for } t \in[a, b] .
$$

Theorem 1.3 Let (3) hold and the homogeneous problem (1a), (2) have a nontrivial solution $u_{0}$. Then the problem (1), (2), where the function q satisfies (4), is solvable iff the condition

$$
\int_{a}^{b} q(s) u_{0}(s) d s=0
$$

is fulfilled.

Remark 1.2 In view of Remark 1.1 and condition (4), the function $q u_{0}$ is integrable on $[a, b]$ and, therefore, condition (5) is meaningful.

\section{Auxiliary statements}

First of all, for convenience of references, we recall two lemmas from [1]. 
Lemma 2.1 ([1, Lemma 2.1]) Let (3) and (4) hold. Then, for any $\alpha \in[a, b[$ and $\beta \in] \alpha, b]$, every solution $u$ of equation (1) satisfying

$$
u(\alpha)=0, \quad u(\beta)=0
$$

admits the estimate

$$
\begin{aligned}
(t-a)(b-t)\left|u^{\prime}(t)\right| \leq & \|u\|_{[\alpha, \beta]}\left(b-a+\int_{a}^{b}(s-a)(b-s)[p(s)]_{-} d s\right) \\
& \left.+\int_{a}^{b}(s-a)(b-s)|q(s)| d s \quad \text { for } t \in\right] \alpha, \beta[.
\end{aligned}
$$

Lemma 2.2 ([1, Lemma 2.2]) Let (3) hold. Then there exist $\left.a_{0} \in\right] a, b\left[, b_{0} \in\right] a_{0}, b[$, and $\varrho>0$ such that, for any $\alpha \in\left[a, a_{0}[, \beta \in] b_{0}, b\right]$, and $q$ satisfying (4), every solution $u$ of equation (1) satisfying

$$
u(\alpha)=0
$$

admits the estimate

$$
\left.\left.|u(t)| \leq \varrho\left((t-a)\|u\|_{\left[\alpha, a_{0}\right]}+\int_{a}^{t}(s-a)|q(s)| d s+(t-a) \int_{t}^{a_{0}}|q(s)| d s\right) \quad \text { for } t \in\right] \alpha, a_{0}\right]
$$

while every solution $u$ of equation (1) satisfying

$$
u(\beta)=0
$$

admits the estimate

$$
|u(t)| \leq \varrho\left((b-t)\|u\|_{\left[b_{0}, \beta\right]}+\int_{t}^{b}(b-s)|q(s)| d s+(b-t) \int_{b_{0}}^{t}|q(s)| d s\right) \quad \text { for } t \in\left[b_{0}, \beta[.\right.
$$

Next proposition immediately follows from Lemma 2.2.

Proposition 2.1 Let (3) hold and $u_{0}$ be a nontrivial solution of the homogeneous problem (1a), (2). Then there exists $r_{0}>0$ such that

$$
\left|u_{0}(t)\right| \leq r_{0}(t-a)(b-t) \quad \text { for } t \in[a, b] .
$$

Proposition 2.2 Let (3) hold and $u_{0}$ be a nontrivial solution of (1a) satisfying $u_{0}(a)=0$ (respectively, $\left.u_{0}(b)=0\right)$. Then there exists $\left.a_{1} \in\right] a, b\left[\right.$ (respectively, $\left.b_{1} \in\right] a, b[$ ) such that

$$
\left.\left.u_{0}(t) \neq 0 \quad \text { for } t \in\right] a, a_{1}\right] \quad \text { (respectively, } \quad u_{0}(t) \neq 0 \quad \text { for } t \in\left[b_{1}, b[) .\right.
$$

Proof In view of (3) there exists $\left.a_{0} \in\right] a, b\left[\right.$ (respectively, $\left.b_{0} \in\right] a, b[$ ) such that

$$
\int_{a}^{a_{0}}(s-a)[p(s)]_{-} d s<1 \quad\left(\text { respectively, } \quad \int_{b_{0}}^{b}(b-s)[p(s)]_{-} d s<1\right) .
$$


Hence, the inequality

$$
\begin{aligned}
& \int_{a}^{a_{0}}(s-a)\left(a_{0}-s\right)[p(s)]_{-} d s<a_{0}-a \\
& \left(\text { respectively, } \int_{b_{0}}^{b}\left(s-b_{0}\right)(b-s)[p(s)]_{-} d s<b-b_{0}\right)
\end{aligned}
$$

holds, as well. The latter inequality, by virtue of [2, Lemma 4.1], implies that for any $a<$ $t_{1}<t_{2}<a_{0}$ (respectively, $b_{0}<t_{1}<t_{2}<b$ ), the problem

$$
u^{\prime \prime}=p(t) u ; \quad u\left(t_{1}\right)=0, \quad u\left(t_{2}\right)=0
$$

has no nontrivial solution.

Now suppose that $u_{0}$ is a nontrivial solution of (1a) satisfying $u_{0}(a)=0$ (respectively, $\left.u_{0}(b)=0\right)$. Then it follows from the above that either

$$
\left.\left.u_{0}(t) \neq 0 \quad \text { for } t \in\right] a, a_{0}\right] \quad \text { (respectively, } \quad u_{0}(t) \neq 0 \text { for } t \in\left[b_{0}, b[)\right. \text {, }
$$

or there is a $\left.\left.t_{0} \in\right] a, a_{0}\right]$ (respectively, $t_{0} \in\left[b_{0}, b[\right.$ ) such that

$$
\begin{aligned}
& \left.u_{0}(t) \neq 0 \quad \text { for } t \in\right] a, t_{0}\left[, \quad u_{0}\left(t_{0}\right)=0\right. \\
& \text { (respectively, } \left.\quad u_{0}(t) \neq 0 \quad \text { for } t \in\right] t_{0}, b\left[, \quad u_{0}\left(t_{0}\right)=0\right. \text { ). }
\end{aligned}
$$

It is now clear that (6) holds with $a_{1}=a_{0}$ (respectively, $b_{1}=b_{0}$ ) if (7) holds, and with $a_{1}=\frac{a+t_{0}}{2}$ (respectively, $b_{1}=\frac{t_{0}+b}{2}$ ) if (8) is satisfied.

Lemma 2.3 Let (3) and (4) hold. Let, moreover, $u$ be a solution of the problem (1), (2) and $u_{0}$ be a solution of the problem (1a), (2). Then

$$
\lim _{t \rightarrow a+}\left(u^{\prime}(t) u_{0}(t)-u(t) u_{0}^{\prime}(t)\right)=0, \quad \lim _{t \rightarrow b-}\left(u^{\prime}(t) u_{0}(t)-u(t) u_{0}^{\prime}(t)\right)=0 .
$$

Proof It is clear that

$$
\left.\left(u^{\prime}(t) u_{0}(t)-u(t) u_{0}^{\prime}(t)\right)^{\prime}=q(t) u_{0}(t) \quad \text { for } t \in\right] a, b[
$$

Hence,

$$
\left.u^{\prime}(t) u_{0}(t)-u(t) u_{0}^{\prime}(t)=\delta-\int_{t}^{c} q(s) u_{0}(s) d s \quad \text { for } t \in\right] a, b[
$$

where

$$
c=\frac{a+b}{2} \quad \text { and } \quad \delta=u^{\prime}(c) u_{0}(c)-u(c) u_{0}^{\prime}(c)
$$

By virtue of Proposition 2.1 and condition (4), the function $q u_{0}$ is integrable on $[a, b]$. Thus, it follows from (10) that there exists a finite limit

$$
\lim _{t \rightarrow a+}\left|u^{\prime}(t) u_{0}(t)-u(t) u_{0}^{\prime}(t)\right|=\varepsilon_{0}
$$


Now we will show that $\varepsilon_{0}=0$. Suppose the contrary, let

$$
\varepsilon_{0}>0
$$

Then there is $\alpha \in] a, b[$ such that

$$
\left.\left.\left|u^{\prime}(t) u_{0}(t)-u(t) u_{0}^{\prime}(t)\right|>\frac{\varepsilon_{0}}{2} \quad \text { for } t \in\right] a, \alpha\right]
$$

On account of Proposition 2.2, we can assume without loss of generality that

$$
\left.\left.u_{0}(t) \neq 0 \quad \text { for } t \in\right] a, \alpha\right]
$$

Then it follows from (13) that

$$
\left.\left.\left|\left(\frac{u(t)}{u_{0}(t)}\right)^{\prime}\right|>\frac{\varepsilon_{0}}{2 u_{0}^{2}(t)} \quad \text { for } t \in\right] a, \alpha\right]
$$

Hence

$$
\left.\left.\left|\mu u_{0}(t)-u(t)\right|>\frac{\varepsilon_{0}}{2}\left|u_{0}(t)\right| \int_{t}^{\alpha} \frac{d s}{u_{0}^{2}(s)} \quad \text { for } t \in\right] a, \alpha\right],
$$

where $\mu=\frac{u(\alpha)}{u_{0}(\alpha)}$

Taking now into account Proposition 2.1, we get from (15) that

$$
\left.\left.\left|\mu u_{0}(t)-u(t)\right|>\varepsilon_{1}\left|u_{0}(t)\right|\left(\frac{1}{t-a}-\frac{1}{\alpha-a}\right) \text { for } t \in\right] a, \alpha\right]
$$

where $\varepsilon_{1}=\frac{\varepsilon_{0}}{2 r_{0}^{2}(b-a)^{2}}$. The latter inequality, in view of the conditions $u_{0}(a)=0$ and $u(a)=0$, implies that

$$
\lim _{t \rightarrow a+} \frac{\left|u_{0}(t)\right|}{t-a}=0
$$

On the other hand, by virtue of Lemma 2.1, there is $M>0$ such that

$$
\left.\left.(t-a)\left|u^{\prime}(t)\right| \leq M \quad \text { for } t \in\right] a, \alpha\right] .
$$

In view of (16) and (17), we get

$$
\lim _{t \rightarrow a+}\left|u^{\prime}(t) u_{0}(t)\right|=\lim _{t \rightarrow a+}(t-a)\left|u^{\prime}(t)\right| \frac{\left|u_{0}(t)\right|}{t-a}=0,
$$

and therefore, on account of (11), we obtain

$$
\lim _{t \rightarrow a+}\left|u(t) u_{0}^{\prime}(t)\right|=\varepsilon_{0} .
$$

Now, let $\left.\alpha_{0} \in\right] a, \alpha[$ be such that

$$
\left.\left.\left|u(t) u_{0}^{\prime}(t)\right|>\frac{\varepsilon_{0}}{2} \quad \text { for } t \in\right] a, \alpha_{0}\right]
$$


Then it is clear that

$$
\left.\left.\|u\|_{[a, b]}\left|u_{0}^{\prime}(t)\right|>\frac{\varepsilon_{0}}{2} \quad \text { for } t \in\right] a, \alpha_{0}\right]
$$

and consequently

$$
\left.\left.\|u\|_{[a, b]}\left|u_{0}(t)\right|>\frac{\varepsilon_{0}}{2}(t-a) \quad \text { for } t \in\right] a, \alpha_{0}\right] .
$$

However, the latter inequality and (16) yield that $\varepsilon_{0} \leq 0$, which contradicts (12). The contradiction obtained proves the first equality in (9). By the same arguments one can prove the second equality in (9).

We will need the next lemma in the proof of the sufficiency part of Theorem 1.3 and thus, we will suppose that Theorem 1.2 and the necessity part of Theorem 1.3 are true.

Lemma 2.4 Let (3) hold and the homogeneous problem (1a), (2) have a nontrivial solution $u_{0}$. Then there exist $n_{0} \in \mathbb{N}$ and $r>0$ such that, for any $q$ satisfying (4) and (5) and every $n>n_{0}$, the solution $u$ of the problem

$$
u^{\prime \prime}=\left(p(t)+\frac{1}{n}[p(t)]_{-}\right) u+q(t) ; \quad u(a)=0, \quad u(b)=0
$$

admits the estimate

$$
|u(t)| \leq r \int_{a}^{b}(s-a)(b-s)|q(s)| d s \quad \text { for } t \in[a, b] .
$$

Proof Suppose the contrary, let the assertion of the lemma be violated. Then, for any $n \in$ $\mathbb{N}$, there exist $k_{n} \geq n, q_{n} \in L_{\mathrm{loc}}(] a, b[)$, and $u_{n} \in A C_{\mathrm{loc}}^{\prime}(] a, b[)$ such that

$$
\begin{aligned}
& \int_{a}^{b}(s-a)(b-s)\left|q_{n}(s)\right| d s<+\infty, \quad \int_{a}^{b} q_{n}(s) u_{0}(s) d s=0, \\
& \left.u_{n}^{\prime \prime}(t)=\left(p(t)+\frac{1}{k_{n}}[p(t)]_{-}\right) u_{n}(t)+q_{n}(t) \quad \text { for } t \in\right] a, b[ \\
& u_{n}(a)=0, \quad u_{n}(b)=0
\end{aligned}
$$

and

$$
\left\|u_{n}\right\|_{[a, b]}>n \int_{a}^{b}(s-a)(b-s)\left|q_{n}(s)\right| d s .
$$

Introduce the notation

$$
\left.\tilde{u}_{n}(t)=\frac{1}{\left\|u_{n}\right\|_{[a, b]}} u_{n}(t), \quad \tilde{q}_{n}(t)=\frac{1}{\left\|u_{n}\right\|_{[a, b]}} q_{n}(t) \quad \text { for } t \in\right] a, b[.
$$

Then it is clear that

$$
\left.\tilde{u}_{n}^{\prime \prime}(t)=\left(p(t)+\frac{1}{k_{n}}[p(t)]_{-}\right) \tilde{u}_{n}(t)+\tilde{q}_{n}(t) \quad \text { for } t \in\right] a, b[,
$$




$$
\begin{aligned}
& \tilde{u}_{n}(a)=0, \quad \tilde{u}_{n}(b)=0, \\
& \left\|\tilde{u}_{n}\right\|_{[a, b]}=1, \\
& \int_{a}^{b}(s-a)(b-s)\left|\tilde{q}_{n}(s)\right| d s<\frac{1}{n}
\end{aligned}
$$

and

$$
\int_{a}^{b} \tilde{q}_{n}(s) u_{0}(s) d s=0
$$

By virtue of Lemma 2.1 (with $\left.q(t)=\frac{1}{k_{n}}[p(t)]_{-} \tilde{u}_{n}(t)+\tilde{q}_{n}(t)\right)$ and (19), we have

$$
\begin{aligned}
(t-a)(b-t)\left|\tilde{u}_{n}^{\prime}(t)\right| \leq & b-a+\frac{n+1}{n} \int_{a}^{b}(s-a)(b-s)[p(s)]_{-} d s \\
& \left.+\int_{a}^{b}(s-a)(b-s)\left|\tilde{q}_{n}(s)\right| d s \quad \text { for } t \in\right] a, b[
\end{aligned}
$$

while, by virtue of Lemma 2.2 (with $q(t)=\frac{1}{k_{n}}[p(t)]_{-} \tilde{u}_{n}(t)+\tilde{q}_{n}(t)$ ), there exist $\left.a_{0} \in\right] a, b[$, $\left.b_{0} \in\right] a_{0}, b[$, and $\varrho>0$ such that

$$
\begin{aligned}
& \left.\left.\left|\tilde{u}_{n}(t)\right| \leq \varrho\left[t-a+\int_{a}^{a_{0}}(s-a)\left|\frac{1}{k_{n}}[p(s)]_{-} \tilde{u}_{n}(s)+\tilde{q}_{n}(s)\right| d s\right] \quad \text { for } t \in\right] a, a_{0}\right], \\
& \left|\tilde{u}_{n}(t)\right| \leq \varrho\left[b-t+\int_{t}^{b}(b-s)\left|\frac{1}{k_{n}}[p(s)]_{-} \tilde{u}_{n}(s)+\tilde{q}_{n}(s)\right| d s\right] \quad \text { for } t \in\left[b_{0}, b[.\right.
\end{aligned}
$$

On account of (19) and (22), the sequence $\left\{u_{n}\right\}_{n=1}^{+\infty}$ is uniformly bounded and equicontinuous in $] a, b$. Thus, by virtue of the Arzelà-Ascoli lemma, we can assume without loss of generality that

$$
\left.\lim _{n \rightarrow+\infty} \tilde{u}_{n}(t)=v_{0}(t) \quad \text { uniformly in }\right] a, b[
$$

where $v_{0} \in C(] a, b[)$ and, moreover,

$$
\lim _{n \rightarrow+\infty} \tilde{u}_{n}^{\prime}\left(\frac{a+b}{2}\right)=c_{0}
$$

In view of $(18)$ it is clear that

$$
\begin{aligned}
\tilde{u}_{n}(t)= & \tilde{u}_{n}\left(\frac{a+b}{2}\right)+\left(t-\frac{a+b}{2}\right) \tilde{u}_{n}^{\prime}\left(\frac{a+b}{2}\right) \\
& \left.+\int_{\frac{a+b}{2}}^{t}\left(\int_{\frac{a+b}{2}}^{s}\left[\left(p(\xi)+\frac{1}{k_{n}}[p(\xi)]_{-}\right) \tilde{u}_{n}(\xi)+\tilde{q}_{n}(\xi)\right] d \xi\right) d s \quad \text { for } t \in\right] a, b[.
\end{aligned}
$$

Hence, on account of (19), (20), (24), and (25), we get

$$
\left.v_{0}(t)=v_{0}\left(\frac{a+b}{2}\right)+c_{0}\left(t-\frac{a+b}{2}\right)+\int_{\frac{a+b}{2}}^{t}\left(\int_{\frac{a+b}{2}}^{s} p(\xi) v_{0}(\xi) d \xi\right) d s \quad \text { for } t \in\right] a, b[\text {. }
$$


Therefore, $v_{0} \in A C_{\mathrm{loc}}^{\prime}(] a, b[)$ and $v_{0}$ is a solution of equation (1a). On the other hand, it follows from (23), in view of (19), (20), and (24), that

$$
\left.\left.\left|v_{0}(t)\right| \leq \varrho(t-a) \quad \text { for } t \in\right] a, a_{0}\right] \quad \text { and } \quad\left|v_{0}(t)\right| \leq \varrho(b-t) \quad \text { for } t \in\left[b_{0}, b[\text {, }\right.
$$

and thus $v_{0}$ is a solution of the problem (1a), (2).

By virtue of (20) and (23), it is clear that there are $\left.\left.n_{1} \in \mathbb{N}, a_{1} \in\right] a, a_{0}\right]$, and $b_{1} \in\left[b_{0}, b[\right.$ such that

$$
\left|\tilde{u}_{n}(t)\right|<1 \quad \text { for } t \in\left[a, a_{1}\right] \cup\left[b_{1}, b\right], n>n_{1} .
$$

Therefore, $\left\|\tilde{u}_{n}\right\|_{\left[a_{1}, b_{1}\right]}=1$ for $n>n_{1}$. Taking now into account (24), we get that $\left\|v_{0}\right\|_{\left[a_{1}, b_{1}\right]}=1$ and, therefore, $v_{0}$ is a nontrivial solution of the problem (1a), (2).

By virtue of Theorem 1.2, there is $\lambda \neq 0$ such that

$$
\nu_{0}(t)=\lambda u_{0}(t) \quad \text { for } t \in[a, b]
$$

Moreover, in view of the necessity part of Theorem $1.3\left(\right.$ with $\left.q(t)=\frac{1}{k_{n}}[p(t)]_{-} \tilde{u}_{n}(t)+\tilde{q}_{n}(t)\right)$, (18), (19), (21), and (26), we get

$$
\int_{a}^{b}[p(s)]_{-} \tilde{u}_{n}(s) v_{0}(s) d s=0
$$

Let now $\alpha \in] a, b[$ and $\beta \in] \alpha, b[$ be arbitrary. Then, in view of (24), we have

$$
\lim _{n \rightarrow+\infty} \int_{\alpha}^{\beta}[p(s)]_{-} \tilde{u}_{n}(s) v_{0}(s) d s=\int_{\alpha}^{\beta}[p(s)]_{-} v_{0}^{2}(s) d s .
$$

On account of (3), (26), and Proposition 2.1, the function $[p]_{-} v_{0}$ is integrable on $[a, b]$. Taking into account (19), we get

$$
\left|\int_{a}^{\alpha}[p(s)]_{-} \tilde{u}_{n}(s) v_{0}(s) d s\right| \leq \int_{a}^{\alpha}[p(s)]_{-}\left|v_{0}(s)\right| d s
$$

and

$$
\left|\int_{\beta}^{b}[p(s)]_{-} \tilde{u}_{n}(s) v_{0}(s) d s\right| \leq \int_{\beta}^{b}[p(s)]_{-}\left|v_{0}(s)\right| d s .
$$

Hence, (27) implies the inequality

$$
\int_{\alpha}^{\beta}[p(s)]_{-} \tilde{u}_{n}(s) v_{0}(s) d s \leq \int_{a}^{\alpha}[p(s)]_{-}\left|v_{0}(s)\right| d s+\int_{\beta}^{b}[p(s)]_{-}\left|v_{0}(s)\right| d s,
$$

which, together with (28), results in

$$
\int_{\alpha}^{\beta}[p(s)]_{-} v_{0}^{2}(s) d s \leq \int_{a}^{\alpha}[p(s)]_{-}\left|v_{0}(s)\right| d s+\int_{\beta}^{b}[p(s)]_{-}\left|v_{0}(s)\right| d s .
$$


Since $\alpha$ and $\beta$ were arbitrary, we get from the latter inequality that

$$
\int_{a}^{b}[p(s)]_{-} v_{0}^{2}(s) d s=0 .
$$

Taking now into account that $v_{0} \not \equiv 0$, we get $[p]_{-} \equiv 0$, i.e., $p(t) \geq 0$ for $\left.t \in\right] a, b[$. However, in this case the problem (1a), (2) has no nontrivial solution, which contradicts the assumption of the lemma.

\section{Proofs}

Proof of Theorem 1.2 Let $u_{0}$ and $v_{0}$ be any nontrivial solutions of (1a). By virtue of Lemma 2.3 (with $u \equiv v_{0}$ and $q \equiv 0$ ), we get

$$
\lim _{t \rightarrow a+}\left(u_{0}^{\prime}(t) v_{0}(t)-u_{0}(t) v_{0}^{\prime}(t)\right)=0
$$

On the other hand, clearly

$$
\left.\left(u_{0}^{\prime}(t) v_{0}(t)-u_{0}(t) v_{0}^{\prime}(t)\right)^{\prime}=0 \quad \text { for } t \in\right] a, b[
$$

and, therefore,

$$
u_{0}^{\prime}(t) v_{0}(t)-u_{0}(t) v_{0}^{\prime}(t)=0 \quad \text { for } t \in[a, b] .
$$

Choose $\left.t_{0} \in\right] a, b[$ such that

$$
u_{0}^{\prime}\left(t_{0}\right)=0
$$

It is clear that $u_{0}\left(t_{0}\right) \neq 0$ since otherwise $u_{0} \equiv 0$. Then it follows from (29) that

$$
v_{0}^{\prime}\left(t_{0}\right)=0
$$

and as above $v_{0}\left(t_{0}\right) \neq 0$. Put $\lambda=\frac{u_{0}\left(t_{0}\right)}{v_{0}\left(t_{0}\right)}$ and

$$
w(t)=u_{0}(t)-\lambda v_{0}(t) \quad \text { for } t \in[a, b] .
$$

Evidently, $w$ is a solution of equation (1a) and $w\left(t_{0}\right)=0$. However, it follows from (29) that $w^{\prime}\left(t_{0}\right)=0$. Consequently, $w \equiv 0$ and thus $u_{0} \equiv \lambda v_{0}$.

Proof of Theorem 1.3 Let $u_{0}$ be a nontrivial solution of (1a), (2) while $u$ be a solution of (1), (2). Put

$$
\left.f(t)=u^{\prime}(t) u_{0}(t)-u(t) u_{0}^{\prime}(t) \quad \text { for } t \in\right] a, b[.
$$

It is clear that

$$
\left.f^{\prime}(t)=q(t) u_{0}(t) \quad \text { for } t \in\right] a, b[
$$


Hence,

$$
\left.f\left(\frac{a+b}{2}\right)-f(t)=\int_{t}^{\frac{a+b}{2}} q(s) u_{0}(s) d s \quad \text { for } t \in\right] a, b[
$$

By virtue of Lemma 2.3, Proposition 2.1, and condition (4), we get from (30) that

$$
f\left(\frac{a+b}{2}\right)=\int_{a}^{\frac{a+b}{2}} q(s) u_{0}(s) d s \quad \text { and } \quad f\left(\frac{a+b}{2}\right)=-\int_{\frac{a+b}{2}}^{b} q(s) u_{0}(s) d s
$$

and therefore (5) is fulfilled.

Let now $u_{0}$ be a nontrivial solution of (1a), (2), $q \in L_{\mathrm{loc}}(] a, b[)$ satisfy (4), and (5) be fulfilled. Let, moreover, $n_{0} \in \mathbb{N}$ and $r>0$ be from the assertion of Lemma 2.4. By virtue of Lemma 2.4 , for any $n>n_{0}$, the problem

$$
u^{\prime \prime}=\left(p(t)+\frac{1}{n}[p(t)]_{-}\right) u ; \quad u(a)=0, \quad u(b)=0
$$

has no nontrivial solution. Since

$$
\left[p(t)+\frac{1}{n}[p(t)]_{-}\right]_{-}=\frac{n-1}{n}[p(t)]_{-}
$$

and (3) holds, it follows from Theorem 1.1 that, for any $n>n_{0}$, the problem

$$
u^{\prime \prime}=\left(p(t)+\frac{1}{n}[p(t)]_{-}\right) u+q(t) ; \quad u(a)=0, \quad u(b)=0
$$

has a unique solution $u_{n}$.

In view of Lemma 2.4, the inequalities

$$
\left.\left|u_{n}(t)\right| \leq M \quad \text { for } t \in\right] a, b\left[, n>n_{0}\right.
$$

are fulfilled, where

$$
M=r \int_{a}^{b}(s-a)(b-s)|q(s)| d s
$$

On the other hand, on account of Lemma 2.1, (31), and (33), we get

$$
\left.(t-a)(b-t)\left|u_{n}^{\prime}(t)\right| \leq M_{1} \quad \text { for } t \in\right] a, b\left[, n>n_{0},\right.
$$

where

$$
M_{1}=M\left(b-a+2 \int_{a}^{b}(s-a)(b-s)[p(s)]_{-} d s\right)+\int_{a}^{b}(s-a)(b-s)|q(s)| d s
$$

It follows from (33) and (34) that the sequence $\left\{u_{n}\right\}_{n=n_{0}}^{+\infty}$ is uniformly bounded and equicontinuous in $] a, b[$. Hence, by virtue of the Arzelà-Ascoli lemma, we can assume without loss 
of generality that

$$
\left.\lim _{n \rightarrow+\infty} u_{n}=u(t) \text { uniformly in }\right] a, b[\text {, }
$$

where $u \in C(] a, b[)$ and, moreover,

$$
\lim _{n \rightarrow+\infty} u_{n}^{\prime}\left(\frac{a+b}{2}\right)=c_{0}
$$

In view of (32), it is clear that

$$
\begin{aligned}
u_{n}(t)= & u_{n}\left(\frac{a+b}{2}\right)+\left(t-\frac{a+b}{2}\right) u_{n}^{\prime}\left(\frac{a+b}{2}\right) \\
& \left.+\int_{\frac{a+b}{2}}^{t}\left(\int_{\frac{a+b}{2}}^{s}\left[\left(p(\xi)+\frac{1}{n}[p(\xi)]_{-}\right) u_{n}(\xi)+q(\xi)\right] d \xi\right) d s \quad \text { for } t \in\right] a, b[.
\end{aligned}
$$

Hence, on account of (35) and (36), we get that

$$
\begin{aligned}
u(t)= & u\left(\frac{a+b}{2}\right)+c_{0}\left(t-\frac{a+b}{2}\right) \\
& \left.+\int_{\frac{a+b}{2}}^{t}\left(\int_{\frac{a+b}{2}}^{s}[p(\xi) u(\xi)+q(\xi)] d \xi\right) d s \quad \text { for } t \in\right] a, b[.
\end{aligned}
$$

Therefore, $u \in A C_{\mathrm{loc}}^{\prime}(] a, b[)$ and $u$ is a solution of equation (1).

On the other hand, by virtue of Lemma 2.2 and (33), there are $\left.a_{0} \in\right] a, b\left[, b_{0} \in\right] a_{0}, b[$, and $\varrho>0$ such that, for any $n>n_{0}$, the inequalities

$$
\begin{aligned}
\left|u_{n}(t)\right| \leq & \varrho\left[M(t-a)+\int_{a}^{t}(s-a)\left(\frac{M}{n}[p(s)]_{-}+|q(s)|\right) d s\right. \\
& \left.\left.\left.+(t-a) \int_{t}^{a_{0}}\left(\frac{M}{n}[p(s)]_{-}+|q(s)|\right) d s\right] \text { for } t \in\right] a, a_{0}\right]
\end{aligned}
$$

and

$$
\begin{aligned}
\left|u_{n}(t)\right| \leq & \varrho\left[M(b-t)+\int_{t}^{b}(b-s)\left(\frac{M}{n}[p(s)]_{-}+|q(s)|\right) d s\right. \\
& \left.+(b-t) \int_{b_{0}}^{t}\left(\frac{M}{n}[p(s)]_{-}+|q(s)|\right) d s\right] \text { for } t \in\left[b_{0}, b[\right.
\end{aligned}
$$

are fulfilled. Hence, in view of (35), we get

$$
\left.\left.|u(t)| \leq \varrho\left[M(t-a)+\int_{a}^{t}(s-a)|q(s)| d s+(t-a) \int_{t}^{a_{0}}|q(s)| d s\right] \quad \text { for } t \in\right] a, a_{0}\right]
$$

and

$$
|u(t)| \leq \varrho\left[M(b-t)+\int_{t}^{b}(b-s)|q(s)| d s+(b-t) \int_{b_{0}}^{t}|q(s)| d s\right] \text { for } t \in\left[b_{0}, b[.\right.
$$

Consequently, $u$ satisfies (2) and thus $u$ is a solution of the problem (1), (2). 
Competing interests

The authors declare that they have no competing interests.

\section{Authors' contributions}

All authors read and approved the final manuscript.

\section{Author details}

${ }^{1}$ Institute of Mathematics, Academy of Sciences of the Czech Republic, branch in Brno, Žižkova 22, Brno, 616 62, Czech Republic. ${ }^{2}$ Institute of Mathematics, Faculty of Mechanical Engineering, Brno University of Technology, Technická 2, Brno, 616 69, Czech Republic

\section{Acknowledgements}

Published results were supported by the project 'Popularization of BUT R\&D results and support systematic collaboration with Czech students' CZ.1.07/2.3.00/35.0004 and by the project NETME CENTRE PLUS (LO1202). The results of this project NETME CENTRE PLUS (LO1202) were co-funded by the Ministry of Education, Youth and Sports within the support programme 'National Sustainability Programme l'. Research was also supported by RVO: 67985840.

Received: 13 September 2013 Accepted: 14 February 2014 Published: 18 Mar 2014

\section{References}

1. Lomtatidze, A, Opluštil, Z: Fredholm alternative for the second-order singular Dirichlet problem. Bound. Value Probl. 2014, 13 (2014). doi:10.1186/1687-2770-2014-13

2. Kiguradze, IT, Shekhter, BL: Singular boundary value problems for second-order ordinary differential equations. J. Sov. Math. 43(2), 2340-2417 (1988)

10.1186/1687-2770-2014-59

Cite this article as: Lomtatidze and Opluštil: Fredholm's third theorem for second-order singular Dirichlet problem. Boundary Value Problems 2014, 2014:59

\section{Submit your manuscript to a SpringerOpen ${ }^{\ominus}$ journal and benefit from:}

- Convenient online submission

- Rigorous peer review

- Immediate publication on acceptance

- Open access: articles freely available online

- High visibility within the field

- Retaining the copyright to your article 